\title{
Text message reminders to improve questionnaire response rates in RCTs: findings from three randomised sub-studies
}

\author{
Ada Keding ${ }^{1 *}$, Sally Brabyn ${ }^{1}$, Hugh MacPherson ${ }^{1}$, Stewart Richmond², David Torgerson ${ }^{1}$ \\ From 3rd International Clinical Trials Methodology Conference \\ Glasgow, UK. 16-17 November 2015
}

\section{Background}

Valid treatment effect estimates in the analysis of RCTs using patient reported outcomes depend on adequate response rates. Losses to follow-up are often high, and inexpensive ways to improve retention are much sought.

\section{Aim}

To assess the effectiveness of reminders sent by SMS text messages before or after questionnaire distribution on patient response rate and time to response in a mental health trial population.

\section{Methods}

Three randomised sub-studies were embedded in the UK ACUDep trial at three follow-up points. 523 patients of 755 in the main trial consented to being contacted by text message and were randomised to a pre-questionnaire reminder or no reminder at 3 months, a pre-reminder or post-reminder at 6 months and a post-reminder or no reminder at 9 months. Chi square tests and time-to event analyses were used to assess attrition between groups.

\section{Results}

Return rates for pre-reminder SMS were not significantly different at 3 months compared to no reminder $(82.9 \%$ vs $84.7 \%, \mathrm{p}=.580$ ), but showed significantly lower response rates at 6 months compared to post-reminders $(75.2 \%$ vs $83.2 \%, \mathrm{p}=.025)$. Return rates following post-reminders did not significantly differ at 9 months from no reminders (77.1\% vs $78.5 \%, \mathrm{p}=.691$ ). Median times to response ranged from 18 to 25 days, with only returns at 6 months being

University of York, York, UK

Full list of author information is available at the end of the article significantly superior for patients receiving post-reminders ( $\log$-rank test $\mathrm{p}=.044)$.

\section{Conclusions}

Overall, SMS text reminders did not appear to substantially improve patient response rates, although the pattern of effects for reminders sent before or after questionnaire distribution was inconclusive.

\section{Authors' details \\ 'University of York, York, UK. ${ }^{2}$ Sydera Research Associates, Market Weighton, UK.}

Published: 16 November 2015

doi:10.1186/1745-6215-16-S2-P103

Cite this article as: Keding et al.: Text message reminders to improve questionnaire response rates in RCTs: findings from three randomised sub-studies. Trials 2015 16(Suppl 2):P103.
Submit your next manuscript to BioMed Central and take full advantage of:

- Convenient online submission

- Thorough peer review

- No space constraints or color figure charges

- Immediate publication on acceptance

- Inclusion in PubMed, CAS, Scopus and Google Scholar

- Research which is freely available for redistribution
() Biomed Central 